\title{
Correspondence
}

\section{Information requirements of people with dementia}

Sir: We were interested to read the article by Clafferty on the arguments for and against telling patients with Alzheimer's disease information about their diagnosis (Psychiatric Bulletin. July $1999,23,394-395)$. We recently carried out a preliminary study to ascertain the views of patients on this topic. Thirty patients, with a variety of clinical forms of dementia from mild to moderately severe degrees of impairment, consented to be interviewed. They were asked what they would like to know about their illness. Nine patients (30\%) clearly indicated they had no wish to receive any information about their illness. Of the 21 patients $(70 \%)$ who wanted to know more information, the most common requests were for diagnosis and cause of the condition ( 11 patients), the possibility of improvement (five patients) and an explanation of specific symptoms (three patients). Other questions included 'How long will I suffer?' and 'Why me?' Four patients were not able to explain what information they would have liked. When asked from whom they would expect to receive this information, $60 \%$ expected it to come from a doctor, $20 \%$ from another member of the clinical team and $20 \%$ would expect to be told this type of information by a family member.

We suggest that diagnostic information is not forced onto reluctant patients. Considerable care is needed in what information is imparted and how it is delivered. Patients with dementia expect us to discuss more than just their diagnosis with them.

MAREK MARZANSKI, Specialist Registrar in Psychiatry, Penn Hospital, Wolverhampton WV4 $5 H N$; and DAVID BATTIN, Consultant in Old Age Psychiatry, Newtown Hospital, Worcester WR5 1JG.

\section{Atypical neuroleptics and elderly patients with dementia}

Sir: Drs Wismayer \& Sipos have demonstrated hopeful findings of what can be achieved in monitoring the prescription of neuroleptics to patients with dementia (Psychiatric Bulletin. July 1999, 23, 409-412).

However, they misquote me (Thacker \& Jones, 1997) as the percentages they quote refer to the proportion of patients with dementia receiving greater than $50 \mathrm{mg}$ chlorpromazine equivalent of standard neuroleptics (32\% in nursing/ residential care and $23 \%$ living in their own homes).

The clinical standards on neuroleptic prescribing in dementia described by Wismayer \& Sipos make no mention of appropriate neuroleptic dosages. It would be interesting to know whether closer follow-up of prescribing led to dose reductions in the 1996 survey compared with that of 1995.

I note the increasing use of sulpiride at Bristol. Many old age psychiatrists now favour atypical antipsychotic drugs for their elderly patients. Prescribing patterns are, therefore, in a state of flux over time and wide geographical variation due to both different consultant opinions and the geographical lottery involved in the funding of atypical neuroleptics.

However, there is emerging evidence of a more beneficial profile of both short- and long-term side-effects with atypical drugs compared with low doses of standard neuroleptics in older patients (Jeste et al, 1999). On the basis of first doing no harm, the availability of atypical neuroleptics to patients with dementia is probably a more important issue than that of anticholinesterase inhibitors.

\section{References}

Jeste, D. V., Lacro, J. P., Bailey, A., et al (1999) Low incidence of tardive dyskinesia with risperidone compared with haloperidol in older patients. Journal of the American Geriatric Society, 47, 716-710.

THACKER, S. \& JONES, R. (1997) Neuroleptic prescribing to the community elderly in Nottingham. International Journal of Geriatric Psychiatry. 12. 833-837.

S. THACKER, Consultant in Old Age Psychiatry, Mapleton Day Hospital, Derby City General Hospital, Uttoxeter Road, Derby DE22 3NE

\section{Mental Health Act and adult attention-deficit disorder}

Sir: Recently a patient under my care was discharged from a Section 3 by a mental health review tribunal on the grounds that his diagnosis did not constitute evidence for a mental illness under Section 1 of the Mental Health Act 1983.

For some years previously, the patient had been managed as a case of atypical bipolar affective disorder, but another consultant in my trust bravely had put forward the hypothesis 
that, in fact, he was suffering from adult attention-deficit disorder-on the grounds of his combination of restless overactivity and grossly impaired attention, with disinhibition in social relationships, impulsive flouting of social rules and constant interruptions during any form of conversation.

The patient's antipsychotic medication was stopped and he was commenced on a trial of methylphenidate within dose guidelines of 0.6$1.01 \mathrm{mg} / \mathrm{kg}$. When his daily dose reached a stable level of $80 \mathrm{mg}$ daily, his attention span increased markedly over a period of about a week. He became less disruptive within the locked ward environment where he had been managed for some months and realistic plans for his graded return to the family environment were entailed. Family illness had slowed this process down and we were hoping for an agreement for a discharge from Section deferred for one to two weeks.

Unfortunately, after hearing the answers to the initial statutory questions on diagnosis, the tribunal adjourned immediately and subsequently was unwilling to hear further evidence on the progress of treatment and social circumstances. The tribunal felt obliged to recommend that the patient concerned was illegally detained because the diagnosis was not a recognised mental disorder in Britain.

Informally, the tribunal members told me that, as an unwritten rule of thumb, the ICD-10 (World Health Organization, 1992) is used as guidance on whether a disorder or diagnosis constitutes a mental disorder or mental illness within the meaning of Section 1 of the Mental Health Act. Reference in ICD-10 to adult attention-deficit disorder is in the chapter on disorders of childhood and adolescence, coded under F90.

Increasingly, adult attention-deficit disorder is recognised within the world literature as an entity which adult psychiatrists will be called upon to treat (Biederman et al, 1993; Mannuzza et al, 1998). The concept has a lot of face validity and, given the disruptive nature of the behaviour. it is inevitable that patients with this diagnosis will appear before Mental Health Act review tribunals with increasing frequency. It would be extremely worrying if the events described above were to be replicated across the country as there are many circumstances where it would be very difficult to treat the more severe forms of this disorder on a purely voluntary basis.

\section{References}

Biederman, J., Faraone, S. V., SPencer, T., et al (1993) patterns of psychiatric comorbidity, cognition, and psychosocial functioning in adults with attention deficit hyperactivity disorder. American Journal of Psychiatry, 150, 1792-1798.
Mannuzza, S., Kiein, R. G., Bessler, A., et al (1998) Adult psychiatric status of hyperactive boys grown up. American Journal of Psychiatry. 155, 493-498.

WORLD HEALTH ORGANIZATION (1992) The Tenth Revision of the International Classification of Diseases and Related Disorders. (ICD-10). Geneva: WHO.

ANTONY S. HALE, Consultant Psychiatrist of Mental Illness, Kent Institute of Medicine and Health Sciences, Kent Research and Development Centre, University of Kent at Canterbury, Canterbury, Kent CT2 7PD

\section{Exam results in the 21st century}

Sir: The Royal College of Psychiatrists continues to publish exam results through a list of successful candidates pinned to a noticeboard in the College. A duplicate list is put up in Edinburgh and candidates are sent their results by post the day before (with the usual variation, therefore, in when they actually receive the same). Many rotations organise interviews on or about the date of these results. In order, for example, to be able to calculate the number of Senior House Officer/Level 1 posts available the interview panel needs to know how many existing trainees have passed their Part 1 Examination. This is inevitably competition for applicants and those schemes which interview closest to the date of the results are more likely to be in a position to appoint the best candidates.

We suggest that this present method of publishing examination results by the College is unsatisfactory from all points of view. The process is neither fully public nor private and falls uneasily and inefficiently between the two. The fact that London-based schemes are able to acquire the information they require with relative ease compared with other parts of the country also does little to counter the charge of a 'London bias' which the College is accused of by many (although perhaps this should be a 'Capital bias' given the above).

Surely it would be better if, in common with other Royal Colleges, ours was to avail itself of the opportunity to make effective and practical use of the Internet and publish examination results on its website. The Internet is becoming a commonplace tool used by clinicians in a variety of ways as recognised and supported, at least rhetorically, by the College itself and by the expectation that Internet access be available in all teaching centres.

Is the College going to grasp this nettle or are we going to be stuck with the drawing pins into the 21 st century?

N. H. P. AlLEN, College Tutor, A. BLAKEY, Level 1 Scheme Organiser and College Tutor, B. LARKIN, 